\title{
The Signaling Study of Advance Selling Considering the Product Diffusion and Online Reviews Effect
}

\author{
Xixi Liu \\ Management School, Jinan University, Guangzhou, China \\ Email: 1620225844@qq.com
}

How to cite this paper: Liu, X.X. (2017) The Signaling Study of Advance Selling Considering the Product Diffusion and Online Reviews Effect. Journal of Service Science and Management, 10, 72-86. https://doi.org/10.4236/jssm.2017.101006

Received: December 28, 2016

Accepted: February 25, 2017

Published: February 28, 2017

Copyright $\odot 2017$ by author and Scientific Research Publishing Inc. This work is licensed under the Creative Commons Attribution International License (CC BY 4.0).

http://creativecommons.org/licenses/by/4.0/

\section{(c) (i) Open Access}

\begin{abstract}
With the high-speed development of technology and increasingly fierce competition in the market, many retailers in industries such as computers, smart phones and fashion dress begin to widely adopt the advance selling mode for product selling. Unlike traditional single-stage spot sales mode, we consider a seller who can sell her product over two periods, advance and spot. The seller has private information about the product quality, which is unknown to customers in advance and publicly revealed in spot. The question we consider is which strategy the seller will choose to signal quality in advance and how she can convey a credible signal of product quality. The method that this paper used is signaling game model which is build between retailer and consumer under the influence of product diffusion effect and negative review effect. We find that the price and the e-commerce platform in the advance period are effective tools of signaling product quality. By exploring the problem above, we get some conclusions below: market equilibriums are decided by credibility of the e-commerce platform selected by the high quality product seller. The possibility of equilibrium implementation is affected by the quantity of consumer in pre-selling period, negative review effect coefficient, and the quality of low quality product which can be adjusted market to promote separation equilibrium and avoid confusion equilibrium.
\end{abstract}

\section{Keywords}

Product Diffusion, Negative Review, Advance Selling, Signaling Game, Negative Review

\section{Introduction}

Advance selling becomes popular in recent years, more and more consumers 
who are attracted by convenience and preferential price have trained the habit of advance purchasing. Many high-tech products, electronic products and fashion and other perishable products have used advance selling and normal selling in two periods, such as Amazon and Barnes \& noble presell unlisted electronic books, software, movies, DVDS, music albums, video games and so on. Shugan \& Xie [1] defined advance selling from the perspective of product and service providers, advance selling refers to product or service providers provide consumers with the opportunity to purchase in advance before regular spending period. On the side of product sales business, advance selling can bring many benefits, such as reducing inventory risk, updating demand forecast information according to the booking situation, and reducing the risk of enterprise operation. From a consumer perspective, advance purchasing can not only bring benefits but also bring risks. Consumers can avoid the risk of shortage, at the same time may be associated with price discount or other preferential activities [2]. In addition, consumers can not consult other experience of using new products and experience new products personally, which lead to the result that consumers are not certain about the quality.

Consumers' purchasing behavior is becoming more and more tactical in the face of dynamic pricing [3]. Through the Internet, consumers can get the relevant information of new products conveniently, such as price, supply quantity and suppliers' credit, etc. The strategic purchasing behavior of consumer is the important factor to influence the retailers' decision, which if be ignored, retailers will suffer a great loss [4]. For advance selling of new products, consumers are uncertain about the quality of the new product. Consumers decide whether to purchase in advance or wait on the basis of the information disclosed by sellers. The retailer will determine their message content send to consumers to get the maximum benefit. Thus, a signaling game is formed between the consumers and sellers.

As the rapid development of social media channels, the information communication between consumers is increasingly fluid. Consumers will display and comment on the new product, release and share their consumption experience through the diversified platform (for example, facebook, twitter, etc.). Information flowing between consumer groups will affect the potential consumer's perception and attitude of a product or service, which can result in the change of consumers' purchase preference and decision (i.e., consumer interaction). For example, if some new products are found to have a great booking quantity when consumers browse the amazon [5]. Based on the consumer bandwagon effect result from interaction between consumers, the potential consumers might think that the product is very popular, which can stimulate a strong purchase intention.

In fact, the early academic studies on new products' advance selling is mainly focus on how to use the advance demand information to improve the forecast and inventory planning aspects of the enterprise.

A lot of research mainly discussed the problem of advance selling and demand 
forecasting, such as Li, C., Zhang studied how retailers use the new products' selling information to improve demand forecasting on the premise of rapid response [6]. Gallego, G., Ozer, Boyaci, O. and others mainly considered how manufacturers get the market demand information through advance selling to optimize productivity and maximize profit. The advance demand information usually was got from customer orders in advance [7] [8].

Along with market competition intensifying, the influence of consumer behavior is becoming more and more important. Therefore, recent studies on advance selling strategies began to consider the effect of behavioral factors. Moe discovered that advance demand information will be more valuable when there is strategic consumer behavior. The reason is that these strategic consumers will buy products selectively until clearance sale appearing, which will bring adverse effect to enterprise's profit [9]. Yu Manused the signaling game method to research the problem that there is asymmetric information between seller and strategy consumer. The seller can use rationing capacity in pre-sale period as signal to reveal the quality of products to consumers, it is found that high quality seller allocates a less capacity than low quality sellers so that consumers can distinguish between high quality and low quality products and make purchase decisions [10].

Product diffusion refers to that the products have been adopted by more and more consumers after listed with the passage of time. Consumers' shopping psychology is mainly divided into two categories: convergence and the pursuit of personality. Based on this, two kinds of different shopping behavior have appeared. In turn, consumer behavior will build status signal, shape personal image, and reveal his personality. Other consumers in the market can easily get accurate, detailed information about the product or service. Information flows between consumer groups will affect the potential consumer's perception and attitude to a product or service, which can result in the change of its product purchase preference and purchase decision.

\section{The Theoretical Basis of Signaling Gamed}

Signaling game is a kind of simple, important gamemodel in incomplete information dynamic game model games. There are a lot of applications in the field of economic management. There are two participants in signaling games: the sender of signal is participant 1 , the receiver of signal is participant 2 . The participant 1 knows her private type $\theta$, the probability distribution of $\theta$ is common knowledge for participant 1 and participant 2 .

1) The type of participant 1 is $\in \varnothing$, which is decided by probability distribution $P(\theta) . \varnothing=\left\{\theta_{1}, \theta_{2}, \cdots, \theta_{i}\right\}$ is the space of types.

2) Participant 1 will choose signal $m(\theta) \epsilon M$ after knowing the $\theta$. $M=\left\{M_{1}, M_{2}, \cdots, M_{j}\right\}$ is the signal space for participant 1 .

3) Participant 2 will generate an inference for the type of participant 1 , named posteriori probability $\tilde{P}(\theta \mid m)$ after receiving the signal send by participant 1 . Then, participant 2 will choose an action from $a(M) \in A . A=\left\{A_{1}, A_{2}, \cdots, A_{H}\right\}$ 
is the action space for participant 2 .

In signaling game, the strategy $s_{1}$ of signal sender is the mapping from $\varnothing$ to $M$, the strategy $s_{2}$ of signal receiver is the mapping from $M$ to $A$.

There are two kinds of equilibrium in the application of signaling game: separating equilibrium and pooling equilibrium. Separating equilibrium means different signal senders send different kinds of signals. Pooling equilibrium means different signal senders send the same kind of signal.

\section{The Model}

This paper considers that a single retailer use two period sales model which combined pre-sale period and normal sales period in oligopoly market to sell products whose updating speed and sale cycle is rapid and short. Retailers will deliver pre-sale Consumers are uncertainty about the quality of the product because of the lack of consumer experience in pre-sale period. However, consumers are certain about the quality of the products because of transparent information in the normal sales period. Therefore, retailers need to disclose some information about quality to make consumers decide their action in pre-sale period. In reality, the most direct signal reflecting quality of the product is price. However, there are more and more e-commerce platforms whose credibility is different. So the quality of product is not only reflected by its price, but also by e-commerce platform selected by its retailer. So this paper assumes that the retailer conveys the quality information of the product by delivering signal whose content is price and the credibility of e-commerce platform selected by retailer. The consumers entering the market in pre-sale period will decide to pre-purchase or wait according to the signal they received to maximize their utility. At the same time, the retailer can predict their signal's influence on consumers' buying behavior, so retailer need to make decisions on signaling to maximize its utility. Finally, we can get the conditions of separating equilibrium and pooling equilibrium.

How retailers choose the information they want to send to consumers to influence their own utility (profit)? In this paper, the model takes the product diffusion that is the sales volume during the pre-sale period will influence the sales volume on the normal sales period positively into account. The diffusion effect of high quality product is more obvious than low quality products. Therefore, in order to simplify the research, this paper only considered the product diffusion effect of high quality products. The reliability of the sales volume displayed on the e-commerce platform is decided by the credibility of the e-commerce platform. Hence, the degree of the product diffusion is decided by pre-sale volume and the credibility of the e-commerce platform collectively.

This paper not only considered product diffusion effect, also considered the influence of negative reviews. In reality, consumers can clearly receive negative review information at e-commerce platforms who have high credibility because of its perfect evaluation system, so the influence of negative review is large. In the same way, the influence of negative review is small at e-commerce platforms 
who have low credibility. Therefore, in order to simplify the research, this paper assumes that negative review effect will not be generated when products is pre-sale in low credit platform. The degree of influence is decided by the difference between the price and the actual quality.

\section{Assumption}

1) Retailer and consumer are the two participants in the signal game of the e-commerce advance selling. Retailer is the sender of signal and consumer is the receiver of signal. Additionally, the type of retailer is private information.

2) There are many types of retailers' classification standards, this paper considers that the retailers need to convey information to signal quality of the products. Thus, retailers can be divided into the high quality retailer and the low quality retailer two types, which are said by $\theta_{1}$ and $\theta_{2}$ respectively. Then, the retailer type space is $\varnothing=\left\{\theta_{1}, \theta_{2}\right\}$. Retailers know their type, but consumers only know its probability distribution.

3) The quality of high quality product is 1 ; The quality of low quality product is $t$.

4) Consumers' evaluation to the product obey uniform distribution between 0 and 1, namely, $\gamma \sim U[0,1]$.

5) Retailers choose a signal from $M=\left\{m_{1}, m_{2}\right\}$ to send under the premise of that retailer knew its type. $m_{1}$ express the signal that "the pre-sale price is $P_{1}^{a}$, the credibility of the e-commerce platform the retailer choose is $\beta(\beta \geq 0)$ ". $m_{2}$ expresses the signal that "the pre-sale price is $P_{2}^{a}$, the credibility of the e-commerce platform the retailer choose is 0 ".

6) Consumers will choose an action from $b \in\{a, w\}$ after receiving the signal.

7) The high quality retailers only signal $m_{1}$; The low quality retailer may send $m_{1}$ or $m_{2}$.

8) The high quality product diffusion effect is influenced by the credibility of the e-commerce platform and quantity of the pre-sale quantity collectively.

9) Consumers won't give negative interview if they receive real signal and choose to purchase in advance; Consumers will give negative interview if they receive false signal and choose to purchase in advance. The negative influence caused by negative reviews is positively proportional with the pre-sale price, and inversely proportional with the quality of the product. Namely, $R=r\left(P_{1}^{a}-V_{L}\right)$.

10) Because the customers in the market are rational, if and only if the utility of buying products is greater than or equal to zero, consumers will buy the product. Hence, the demand quantity of the products in pre-sale period is $D_{i}^{a}=M\left(1-P_{i}^{a}\right)$; The demand quantity of the products in normal sales period is $D_{i}^{s}=N\left(1-P_{i}\right)$.

11) The retailers and consumers all pursue the maximum expected revenue.

Above all, retailers and consumers all pursue the maximum expected revenue. Suggests that $U_{c}\left(\theta_{i}, m_{i}, b\right)$ and $U_{s}\left(\theta_{i}, m_{i}, b\right)$ express consumers' profit function and retailers' profit function separately, the profit function of consumers 
and retailers in various situations is as follows:

$$
\begin{aligned}
& U_{c}\left(\theta_{1}, m_{1}, a\right)=1-P_{1}^{a} \\
& U_{s}\left(\theta_{1}, m_{1}, a\right)=M\left(1-P_{1}^{a}\right)\left(P_{1}^{a}-C_{1}\right)+N(1-P)\left(P-C_{1}\right)+\beta M\left(1-P_{1}^{a}\right)\left(P-C_{1}\right) \\
& U_{c}\left(\theta_{1}, m_{1}, w\right)=1-P \\
& U_{s}\left(\theta_{1}, m_{1}, w\right)=(M+N)(1-P)\left(P-C_{1}\right) \\
& U_{c}\left(\theta_{2}, m_{1}, a\right)=t-P_{1}^{a} \\
& U_{s}\left(\theta_{2}, m_{1}, a\right)=M\left(1-P_{1}^{a}\right)\left(P_{1}^{a}-C_{2}\right)+N(1-\tau P)\left(\tau P-C_{2}\right)-r M\left(1-P_{1}^{a}\right)\left(P_{1}^{a}-V_{L}\right) U_{c}\left(\theta_{2}, m_{1}, w\right)=t-\sigma P \\
& U_{s}\left(\theta_{2}, m_{1}, w\right)=(M+N)(1-\sigma P)\left(\sigma P-C_{2}\right) \\
& U_{c}\left(\theta_{2}, m_{2}, a\right)=t-P_{2}^{a} \\
& U_{s}\left(\theta_{2}, m_{2}, a\right)=M\left(1-P_{2}^{a}\right)\left(P_{2}^{a}-C_{2}\right)+N(1-\sigma P)\left(\sigma P-C_{2}\right) \\
& U_{c}\left(\theta_{2}, m_{2}, w\right)=t-\sigma P \\
& U_{s}\left(\theta_{2}, m_{2}, w\right)=(M+N)(1-\sigma P)\left(\sigma P-C_{2}\right)
\end{aligned}
$$

\section{Equilibrium Analysis}

\subsection{Separating Equilibrium}

Separating equilibrium refers to that different types of retailers choose different signals to send. In this paper, because the high quality retailers just send high quality signal, as long as low quality product retailers send low quality signal, can separating equilibrium realize. The high quality retailers send high quality signal $m_{1}$, The low quality retailers send low quality signal $m_{2}$. In separating equilibrium, the signal can express its quality type accurately.

1) Consumer's strategy behavior

The retailers may send signal that is inconsistent with their own quality, so that consumer's prior probability of high quality retailer is as following:

$$
\begin{array}{ll}
\tilde{P}\left(\theta_{1} \mid m_{1}\right)=1 & \tilde{P}\left(\theta_{1} \mid m_{2}\right)=0 \\
\tilde{P}\left(\theta_{2} \mid m_{2}\right)=1 & \tilde{P}\left(\theta_{1} \mid m_{1}\right)=0
\end{array}
$$

Consumer's strategy is selecting action from $b \in(a, w)$ to maximize utility.

a) When $m=m_{1}$,

$$
\max _{b=a, w} \sum U_{c}\left(\theta_{1}, m_{1}, b\right) \tilde{P}\left(\theta \mid m_{1}\right)=\max \left\{U_{c}\left(\theta_{1}, m_{1}, a\right), U_{c}\left(\theta_{1}, m_{1}, w\right)\right\}
$$

So that, $b\left(m_{1}\right)=a$.

b) When $m=m_{2}$,

$$
\max _{b=a, w} \sum U_{c}\left(\theta, m_{2}, b\right) \tilde{P}\left(\theta \mid m_{2}\right)=\max \left\{U_{c}\left(\theta_{2}, m_{2}, a\right), U_{c}\left(\theta_{2}, m_{2}, w\right)\right\}
$$

So that, $b\left(m_{2}\right)=a$.

Hence, if retailer send real signal, consumer's best strategy to select action according to different signals is as following: $b\left(m_{1}\right)=a ; b\left(m_{2}\right)=a$.

2) Retailer's strategy behavior

Retailer's strategy is to select from $m(a) \in M$ to maximize utility in the basis 
of that consumer's strategy is decided after receiving signal.

a) If $\theta=\theta_{1}$, then $m\left(\theta_{1}\right)=m_{1}$.

b) If $\theta=\theta_{2}$, then

$$
\begin{aligned}
& \max _{m=m_{1}, m_{2}} U_{s}\left(\theta_{2}, m, b\right) \\
& =\max \left\{U_{s}\left(\theta_{2}, m_{1}, a\right), U_{s}\left(\theta_{2}, m_{2}, a\right)\right\}
\end{aligned}
$$

In the following, $e=C_{1}-\beta\left(P-C_{1}\right), G=N(1-\sigma P)\left(\sigma P-C_{2}\right)$. Because $U_{s}\left(\theta_{1}, m_{1}, a\right)=M\left(1-P_{1}^{a}\right)\left(P_{1}^{a}-C_{1}\right)+N(1-P)\left(P-C_{1}\right)+\beta M\left(1-P_{1}^{a}\right)\left(P-C_{1}\right)$, high quality retailer will have a pre-sale pricing to maximize $U_{s}\left(\theta_{1}, m_{1}, a\right)$, thus, $P_{1}^{a}=\frac{1+e}{2}$.

If $m\left(\theta_{2}\right)=m_{1}$, namely, low quality retailer imitate high quality retailer's pre-sale pricing, $U_{s}\left(\theta_{2}, m_{1}, a\right)=M\left(1-\frac{1+e}{2}\right)\left(\frac{1+e}{2}-C_{2}\right)+\left(1-r\left(\frac{1+e}{2}-t\right)\right) G$; If $m\left(\theta_{2}\right)=m_{2}$, namely, low quality retailer doesn't imitate high quality retailer's pre-sale pricing, then low quality retailer will have its own pre-sale pricing to maximize $U_{s}\left(\theta_{2}, m_{2}, a\right), P_{2}^{a}=\frac{t+C_{2}}{2}$. Thus, $U_{s}\left(\theta_{2}, m_{2}, a\right)=M \frac{\left(t-C_{2}\right)^{2}}{4}+G$.

If $U_{s}\left(\theta_{2}, m_{1}, a\right) \geq U_{s}\left(\theta_{2}, m_{1}, a\right)$,

$\frac{M+C_{2} M+G r-\sqrt{G^{2} r^{2}+M^{2}\left(-1+2 C_{2}-t\right)(-1+t)+2 G M r\left(1+C_{2}-2 t\right)}}{2 M}$

$\leq P_{1}^{a} \leq \frac{M+C_{2} M+G r+\sqrt{G^{2} r^{2}+M^{2}\left(-1+2 C_{2}-t\right)(-1+t)+2 G M r\left(1+C_{2}-2 t\right)}}{2 M}$

so that, if

$\frac{-2 \frac{M+C_{2} M+G r+\sqrt{G^{2} r^{2}+M^{2}\left(-1+2 C_{2}-t\right)(-1+t)+2 G M r\left(1+C_{2}-2 t\right)}}{2 M}+1+C_{1}}{P-C_{1}}$

$\leq \beta \leq \frac{-2 \frac{M+C_{2} M+G r-\sqrt{G^{2} r^{2}+M^{2}\left(-1+2 C_{2}-t\right)(-1+t)+2 G M r\left(1+C_{2}-2 t\right)}}{2 M}+1+C_{1}}{P-C_{1}}$, $m\left(\theta_{2}\right)=m_{1}$, otherwise, $m\left(\theta_{2}\right)=m_{2}$.

To sum up, there are several equilibrium strategies as following:

$$
\frac{-2 \frac{M+C_{2} M-G r+\sqrt{G r\left(G r-2 M\left(1+C_{2}-2 t\right)\right)}}{2 M}+1+C_{1}}{P-C_{1}}
$$

$$
\leq \beta \leq \frac{-2 \frac{M+C_{2} M-G r-\sqrt{G r\left(G r-2 M\left(1+C_{2}-2 t\right)\right)}}{2 M}+1+C_{1}}{P-C_{1}}
$$

equilibrium strategy is $\left(\theta_{1}, m_{1}, a\right),\left(\theta_{2}, m_{1}, a\right)$;

2) When $\beta \leq \frac{-2 \frac{M+C_{2} M-G r+\sqrt{G r\left(G r-2 M\left(1+C_{2}-2 t\right)\right)}}{2 M}+1+C_{1}}{P-C_{1}}$ 
or $\beta \geq \frac{-2 \frac{M+C_{2} M-G r-\sqrt{G r\left(G r-2 M\left(1+C_{2}-2 t\right)\right)}}{2 M}+1+C_{1}}{P-C_{1}}$, equilibrium

strategy is $\left(\theta_{1}, m_{1}, a\right),\left(\theta_{2}, m_{2}, a\right)$.

Therefore, the second situation reached a separating equilibrium, we can get the following corollary:

Corollary 1: If the profit of the low quality retailers in normal sales period without the influence of pre-sale strategy $G$ is large, the lower the quality of the low quality product $t$, the greater the possibility of a separating equilibrium; Retailers will pay more attention to the profit of normal sales period when $G$ is large, with $t$ decreasing, the impact of negative review will be larger. Hence, the profit of normal sales period will have more serious loss. In this situation, the low quality retailer tends to send real signal rather than imitate retailer of highquality products, which can lead to a separating equilibrium.

At the same way, if the profit of the low quality retailers in normal sales period without the influence of pre-sale strategy $G$ is small, the higher the quality of the low quality product $t$, the greater the possibility of a separating equilibrium. Retailers will pay more attention to the profit of pre-sale period when $G$ is small, with $t$ increasing, the price in pre-sale period when retailer send real signal. In this situation, the retailer of low-quality products tends to send real signal rather than imitate retailer of high-quality products, which can lead to a separating equilibrium.

$D\left[\frac{M+C_{2} M-G r-\sqrt{G^{2} r^{2}+M^{2}\left(-1+2 C_{2}-t\right)(-1+t)-2 G M r\left(1+C_{2}-2 t\right)}}{2 M}, t\right]$

$=\frac{-C_{2} M+M t-2 G}{2 \sqrt{G^{2} r^{2}+M^{2}\left(-1+2 C_{2}-t\right)(-1+t)-2 G M r\left(1+C_{2}-2 t\right)}}$

If $t \leq C_{2}+\frac{2 G r V_{H}}{M}$, this function is greater with $t$ decreasing.

If $t>C_{2}+\frac{2 G r V_{H}}{M}$, this function is greater with $t$ increasing.

$D\left[\frac{M+C_{2} M-G r+\sqrt{G^{2} r^{2}+M^{2}\left(-1+2 C_{2}-t\right)(-1+t)-2 G M r\left(1+C_{2}-2 t\right)}}{2 M}, t\right]$

$=\frac{C_{2} M-M t+2 G r}{2 \sqrt{G^{2} r^{2}+M^{2}\left(-1+2 C_{2}-t\right)(-1+t)-2 G M r\left(1+C_{2}-2 t\right)}}$

If $t \leq C_{2}+\frac{2 G r V_{H}}{M}$, this function is greater with $t$ increasing.

If $t>C_{2}+\frac{2 G r V_{H}}{M}$, this function is greater with $t$ decreasing.

Corollary 2: If the profit of low quality product retailer in normal sales period without the influence of pre-sale strategy $G$ is large, the larger the $M$ (the quantity of consumers who enter market in pre-sale period), the greater the possibility of a separating equilibrium. For the low quality retailer, the possibility of 
that the increased profit in pre-sale period is more than the loss in normal sales period result from imitating the high quality retailer is small when $G$ is large. In addition, the profit in pre-sale period will increase with $M$ increasing, so that the low quality retailer tends to send real signal, which lead to separating equilibrium.

At the same way, if the profit of low quality product retailer in normal sales period without the influence of pre-sale strategy $G$ is small, the smaller the $M$ (the quantity of consumers who enter the market in pre-sale period), the greater the possibility of a separating equilibrium. For the low quality retailer, the possibility of that the increased profit in pre-sale period is more than the loss in normal sales period result from imitating the high quality retailer is large when $G$ is small. However, the profit in pre-sale period will decrease with $M$ decreasing, so that the low quality retailer tends to send real signal, which lead to separating equilibrium.

$$
\begin{gathered}
D\left[\frac{M+C_{2} M-G r-\sqrt{G^{2} r^{2}+M^{2}\left(-1+2 C_{2}-t\right)(-1+t)-2 G M r\left(1+C_{2}-2 t\right)}}{2 M}, M\right] \\
=\frac{G r\left(G r-M\left(1+C_{2}-2 t\right)+\sqrt{G^{2} r^{2}+M^{2}\left(-1+2 C_{2}-t\right)(-1+t)-2 G M r\left(1+C_{2}-2 t\right)}\right)}{2 M^{2} \sqrt{G^{2} r^{2}+M^{2}\left(-1+2 C_{2}-t\right)(-1+t)-2 G M r\left(1+C_{2}-2 t\right)}} \\
\text { Because }\left(1+C_{2}-2 t\right)^{2} \leq\left(1-2 C_{2}+t\right)(1-t), \\
\frac{G r\left(G r-M\left(1+C_{2}-2 t\right)+\sqrt{G^{2} r^{2}+M^{2}\left(-1+2 C_{2}-t\right)(-1+t)-2 G M r\left(1+C_{2}-2 t\right)}\right)}{2 M^{2} \sqrt{G^{2} r^{2}+M^{2}\left(-1+2 C_{2}-t\right)(-1+t)-2 G M r\left(1+C_{2}-2 t\right)}} \geq 0 .
\end{gathered}
$$

Hence, this function is greater with $M$ decreasing.

$$
\begin{aligned}
& D\left[\frac{M+C_{2} M-G r-\sqrt{G^{2} r^{2}+M^{2}\left(-1+2 C_{2}-t\right)(-1+t)-2 G M r\left(1+C_{2}-2 t\right)}}{2 M}, M\right] \\
& =-\frac{G r\left(G r-M\left(1+C_{2}-2 t\right)-\sqrt{G^{2} r^{2}+M^{2}\left(-1+2 C_{2}-t\right)(-1+t)-2 G M r\left(1+C_{2}-2 t\right)}\right)}{2 M^{2} \sqrt{G^{2} r^{2}+M^{2}\left(-1+2 C_{2}-t\right)(-1+t)-2 G M r\left(1+C_{2}-2 t\right)}}
\end{aligned}
$$

Hence, this function is greater with $M$ increasing.

If $M \leq \frac{G r}{1+C_{2}-2 t V_{H}}$, the speed of left is more rapid than right for the condition of separating equilibrium;

If $M>\frac{G r}{1+C_{2}-2 t V_{H}}$, the speed of left is slower than right for the condition of separating equilibrium.

Corollary 3: The bigger the negative review effect coefficient $r$, the more easy it is to achieve the separating equilibrium. For the low quality retailer, the cost of imitating the high quality retailer is larger with $r$ increasing, so that the low quality retailer will be more willing to send the real signal and achieve the separating equilibrium. 


$$
\begin{aligned}
& D\left[\frac{M+C_{2} M-G r-\sqrt{G^{2} r^{2}+M^{2}\left(-1+2 C_{2}-t\right)(-1+t)-2 G M r\left(1+C_{2}-2 t\right)}}{2 M}, r\right] \\
& =\frac{G\left(-1+\frac{-G r+M\left(1+C_{2}-2 t\right)}{\sqrt{G^{2} r^{2}+M^{2}\left(-1+2 C_{2}-t\right)(-1+t)-2 G M r\left(1+C_{2}-2 t\right)}}\right)}{2 M}
\end{aligned}
$$

this function is greater with $r$ increasing.

$$
\begin{gathered}
D\left[\frac{M+C_{2} M-G r+\sqrt{G^{2} r^{2}+M^{2}\left(-1+2 C_{2}-t\right)(-1+t)-2 G M r\left(1+C_{2}-2 t\right)}}{2 M}, r\right] \\
=\frac{G\left(-1+\frac{G r-M\left(1+C_{2}-2 t\right)}{\sqrt{G^{2} r^{2}+M^{2}\left(1-2 C_{2}+t\right)(1-t)-2 G M r\left(1+C_{2}-2 t\right)}}\right)}{2 M} \\
1+C_{2}-2 t \leq 1-2 C_{2}+t \\
1+C_{2}-2 t \leq 1-t
\end{gathered}
$$

Then, $\left(1+C_{2}-2 t V_{H}\right)^{2} \leq\left(1-2 C_{2}+t\right)(1-t)$,

so that

$G r-M\left(1+C_{2}-2 t V_{H}\right) \leq \sqrt{G^{2} r^{2}+M^{2}\left(1-2 C_{2}+t\right)(1-t)-2 G M r\left(1+C_{2}-2 t V_{H}\right)}$, this function is greater with $r$ decreasing.

\subsection{Pooling Equilibrium}

Pooling equilibrium refers to that the high quality retailer and the low quality retailer choose the same signal to send. However, there is a certain price for the low quality retailer to imitate the high quality retailer. Due to two types of retailers sending the same signal, the signal can't differentiate the retailers. Consumers can't modify prior probability because they can't get new information from the signal transmission. This means that the low quality retailer can cheat consumers by imitating the high quality retailer.

1) Consumer's strategy behavior

The retailers may send signal that is inconsistent with their own quality, so that consumer's prior probability of high quality retailer is as following:

$$
\begin{array}{cc}
\tilde{P}\left(\theta_{1} \mid m_{1}\right)=f \quad \tilde{P}\left(\theta_{2} \mid m_{1}\right)=1-f \\
\tilde{P}\left(\theta_{1} \mid m_{2}\right)=0 \quad \tilde{P}\left(\theta_{2} \mid m_{2}\right)=1 .
\end{array}
$$

a) When $m=m_{1}$, consumers selects their action from $b \in(a, w)$ to maximize utility.

$$
\begin{aligned}
& \max _{b=a, w} \sum_{\theta=\theta_{1}, \theta_{2}} U_{c}\left(\theta, m_{1}, b\right) \tilde{P}\left(\theta \mid m_{1}\right) \\
& =\max _{b=a, w} f U_{c}\left(\theta_{1}, m_{1}, b\right)+(1-f) U_{c}\left(\theta_{2}, m_{1}, b\right) \\
& =\max \left\{f U_{c}\left(\theta_{1}, m_{1}, a\right)+(1-f) U_{c}\left(\theta_{2}, m_{1}, a\right), f U_{c}\left(\theta_{1}, m_{1}, w\right)+(1-f) U_{c}\left(\theta_{2}, m_{1}, w\right)\right\}
\end{aligned}
$$

So that, if $P_{1}^{a} \leq f P+(1-f) t P, b\left(m_{1}\right)=a$; Otherwise, $b\left(m_{1}\right)=w$.

b) When $m=m_{2}$, consumers selects their action from $b \in(a, w)$ to max- 
imize utility.

$$
\begin{aligned}
\max _{b=a, w} \sum_{\theta=\theta_{1}, \theta_{2}} U_{c}\left(\theta, m_{2}, b\right) \tilde{P}\left(\theta \mid m_{2}\right) & =\max _{b=a, w} U_{c}\left(\theta_{2}, m_{2}, b\right) \\
& =\max \left\{U_{c}\left(\theta_{2}, m_{2}, a\right), U_{c}\left(\theta_{2}, m_{2}, w\right)\right\}
\end{aligned}
$$

So that, $b\left(m_{2}\right)=a$.

Hence, if retailer may send false signal, consumer's best strategy to select action according to different signals is as following:

When $P_{1}^{a} \leq f P+(1-f) t P, b\left(m_{1}\right)=a, b\left(m_{2}\right)=a$;

When $P_{1}^{a}>f P+(1-f) t P, b\left(m_{1}\right)=w, b\left(m_{2}\right)=a$.

2) Retailer's strategy behavior

a) In the situation of $P_{1}^{a} \leq f P+(1-f) t P$, namely

$\beta \geq \frac{-2(f P+(1-f) \sigma P)+1+C_{1}}{P-C_{1}}, b\left(m_{1}\right)=a, b\left(m_{2}\right)=a$.

If $\theta=\theta_{1}$, then $m\left(\theta_{1}\right)=m_{1}$.

If $\theta=\theta_{2}$, then

$$
\max _{m=m_{1}, m_{2}} U_{s}\left(\theta_{2}, m, b\right)=\max \left\{U_{s}\left(\theta_{2}, m_{1}, a\right), U_{s}\left(\theta_{2}, m_{2}, a\right)\right\}
$$

This situation is the same with separating equilibrium, so that, if

$U_{s}\left(\theta_{2}, m_{1}, a\right) \geq U_{s}\left(\theta_{2}, m_{2}, a\right)$, namely, if

$$
\begin{aligned}
& \frac{-2 \frac{M+C_{2} M+G r+\sqrt{G^{2} r^{2}+M^{2}\left(-1+2 C_{2}-t\right)(-1+t)+2 G M r\left(1+C_{2}-2 V_{L}\right)}}{2 M}+1+C_{1}}{P-C_{1}} \\
& \leq \beta \\
& \leq \frac{-2 \frac{M+C_{2} M+G r-\sqrt{G^{2} r^{2}+M^{2}\left(-1+2 C_{2}-t\right)(-1+t)+2 G M r\left(1+C_{2}-2 V_{L}\right)}}{2 M}+1+C_{1}}{P-C_{1}}
\end{aligned}
$$

$m\left(\theta_{2}\right)=m_{1}$; Otherwise, $m\left(\theta_{2}\right)=m_{2}$.

b) In the situation of $P_{1}^{a}>f P+(1-f) t P$, namely,

$\beta \geq \frac{-2(f P+(1-f) \sigma P)+1+C_{1}}{P-C_{1}}, b\left(m_{1}\right)=w, b\left(m_{2}\right)=a$.

If $\theta=\theta_{1}$, then $m\left(\theta_{1}\right)=m_{1}$.

If $\theta=\theta_{2}$, then

$$
\max _{m=m_{1}, m_{2}} U_{s}\left(\theta_{2}, m, b\right)=\max \left\{U_{s}\left(\theta_{2}, m_{1}, w\right), U_{s}\left(\theta_{2}, m_{2}, a\right)\right\}
$$

If $m\left(\theta_{2}\right)=m_{1}$, low quality retailer imitate high quality retailer's pre-sale pricing. However, consumers select to wait after receiving $m_{1}$. Hence,

$$
U_{s}\left(\theta_{2}, m_{1}, w\right)=(M+N)(t-\sigma P)\left(\sigma P-C_{2}\right)
$$

If $m\left(\theta_{2}\right)=m_{2}$, low quality retailer doesn't imitate high quality retailer's pre-sale pricing, then low quality retailer will have its own pre-sale pricing to maximize $U_{s}\left(\theta_{2}, m_{2}, a\right), P_{2}^{a}=\frac{t+C_{2}}{2}$. Hence,

$$
U_{s}\left(\theta_{2}, m_{2}, a\right)=M \frac{\left(t-C_{2}\right)^{2}}{4}+N(1-\sigma P)\left(\sigma P-C_{2}\right)
$$


Then, $U_{s}\left(\theta_{2}, m_{1}, w\right) \leq U_{s}\left(\theta_{2}, m_{2}, a\right)$.

So that, $m\left(\theta_{1}\right)=m_{2}$.

To sum up, there are several equilibrium strategies as following:

1) If $\beta \geq \frac{-2(f P+(1-f) \sigma P)+1+C_{1}}{P-C_{1}}$,

When

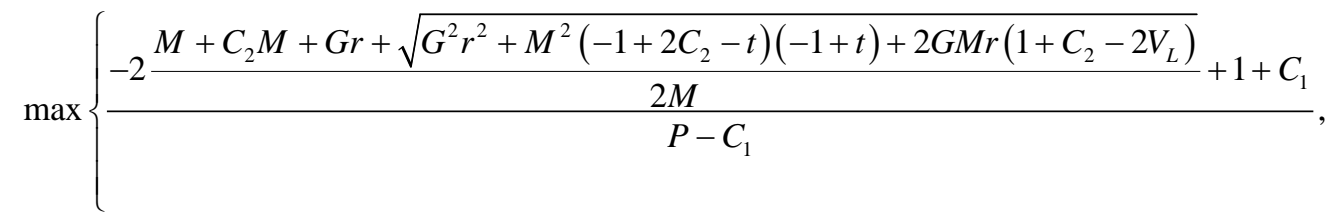

$$
\left.\frac{-2(f P+(1-f) \sigma P)+1+C_{1}}{P-C_{1}}\right\}
$$

$$
\leq \beta \leq \frac{-2 \frac{M+C_{2} M+G r-\sqrt{G^{2} r^{2}+M^{2}\left(-1+2 C_{2}-t\right)(-1+t)+2 G M r\left(1+C_{2}-2 V_{L}\right)}}{2 M}+1+C_{1}}{P-C_{1}}
$$

equilibrium strategy is $\left(\theta_{1}, m_{1}, a\right),\left(\theta_{2}, m_{1}, a\right)$;

2) If $\beta \geq \frac{-2(f P+(1-f) \sigma P)+1+C_{1}}{P-C_{1}}$,

When

$$
\begin{aligned}
\beta \geq \max \left\{\frac{-2 \frac{M+C_{2} M+G r-\sqrt{G^{2} r^{2}+M^{2}\left(-1+2 C_{2}-t\right)(-1+t)+2 G M r\left(1+C_{2}-2 V_{L}\right)}}{2 M}+1+C_{1}}{P-C_{1}},\right. \\
\\
\left.\quad \frac{-2 \frac{(1-f)(1-r) V_{L}+f P-(1-f)\left(V_{L}-\tau P\right)}{f+(1-f)(1-r)}+1+C_{1}}{P-C_{1}}\right\}
\end{aligned}
$$

or

$$
\beta \leq \frac{-2 \frac{M+C_{2} M+G r+\sqrt{G^{2} r^{2}+M^{2}\left(-1+2 C_{2}-t\right)(-1+t)+2 G M r\left(1+C_{2}-2 V_{L}\right)}}{2 M}+1+C_{1}}{P-C_{1}},
$$

equilibrium strategy is $\left(\theta_{1}, m_{1}, a\right),\left(\theta_{2}, m_{2}, a\right)$;

3) If $\beta<\frac{-2(f P+(1-f) \sigma P)+1+C_{1}}{P-C_{1}}$, equilibrium strategy is $\left(\theta_{1}, m_{1}, w\right)$, $\left(\theta_{2}, m_{2}, a\right)$;

Therefore, pooling equilibrium is only reached in the first case. In the first case, the low quality retailer imitates the high quality retailer, and consumers choose to buy in pre-sale period. In this case, the signaling mechanism is a failure, consumers cannot judge the type of retailers from signals send by retailers, so that consumers will be deceived. 
Corollary 1: The possibility of pooling equilibrium is low when consumers have a low prior probability for high quality product which can result in that consumer will choose to wait when they receive a high quality signal. Hence, the low quality retailer tends to send real signal.

The second, the third and the forth corollary is the same with the separating equilibrium.

\section{Conclusions}

From above analysis, the game may achieve separating equilibrium or pooling equilibrium. When separating equilibrium appears, retailers will send real signal according to its type, consumers can distinguish the low quality retailer and the high quality retailer, so that they can choose retailer according to their optimal utility. In this situation, it's not economical for the low quality retailer to imitate the low quality retailer sending $m_{1}$ from the perspective of economic rationality. When pooling equilibrium appears, the increased profit in pre-sale period is more than the loss in normal sale period result from imitating the high quality retailer, so the low quality retailer will imitate the retailer of high quality product. Consumers can only choose their action according to the prior probability because they can't distinguish the two types of retailers in line with signals. The factor that influences the game result is separating equilibrium or pooling equilibrium is the credibility of the e-commerce platform selected by the high quality retailer. The reason for pooling equilibrium is that retailer can get the optimal utility by sending a kind of signal. However, consumers may be cheated in this situation. Thus, separating equilibrium should be encouraged and pooling equilibrium should be avoided.

From above, if we want to reach separating equilibrium and avoid pooling equilibrium, we can take action from the following aspects:

1) When the profit of the low quality retailer in normal sales period without the influence of pre-sale strategy is large, the manufacturers of high quality products should strengthen confidential work of product information in case of being copied by the manufacturers of low quality products. When the profit of low quality product retailer in normal sales period without the influence of pre-sale strategy is small, the government should give some supporting policies to the enterprises of low quality products to encourage the enterprises of low quality products to invest more in research and improving quality.

2) When the number of consumers who enter the market in pre-sale period is small, the e-commerce platform should strengthen the advertising for advance selling to attract more consumers' attention. However, the e-commerce platform should limit for product pre-sale ads when the number of consumers who enter the market in pre-sale period is more than a certain degree.

3) With the popularity of Internet shopping mode, there are more and more e-commerce platform in the market who will all build the consumer evaluation system. Some of the e-commerce platform have clear consumer evaluation system, some other have fuzzy consumer evaluation system platform. The more 
clear the consumer evaluation system, the larger the loss in the normal sale period results from negative interviews. Hence, in order to avoid the pooling equilibrium, the clear and perfect consumer evaluation system should be encouraged.

In the process of setting up model, there is a certain limitation that influences the effectiveness of the interpretation of reality. For example, we assume that the credibility of the e-commerce platform selected by the low quality retailer when he send real signal is zero to reduce the observed variables.

Therefore, in future research, we can consider that the e-commerce platform selected by retailer is positively correlated with the actual quality both for high quality retailer and low quality retailer, then we can have two observed variables, they are the credibility of the e-commerce platform selected by low quality retailer and high quality retailer respectively. In addition, on the basis of this paper, we can consider the situation that there are two retailers who have competition in the market by the same method; we can also make a comparison between monopoly market which is researched in this paper and competitive market.

\section{References}

[1] Xie, J.H. and Shugan, S.M. (2001) Electronic Tickets, Smart Cards, Online Prepayments, When and How to Advance Sell. Marketing Science, 20, 219-243. https://doi.org/10.1287/mksc.20.3.219.9765

[2] Shugan, S.M. and Xie, J. (2004) Advance Selling for Services. California Management Review, 46, 37-54. https://doi.org/10.2307/41166220

[3] Liu, Q. and Van Ryzin, G. (2008) Strategic Capacity Rationing to Induce Early Purchases. Management Science, 54, 1115-1131. https://doi.org/10.1287/mnsc.1070.0832

[4] Prasad, A., Stecke, K. and Zhao, X. (2011) Advance Selling by a Newsvendor Retailer. Production and Operations Management, 20, 129-142. https://doi.org/10.1111/j.1937-5956.2010.01133.x

[5] Su, X. and Zhang, F. (2008) Strategic Customer Behavior, Commitment, and Supply Chain Performance. Management Science, 54, 1759-1773.

https://doi.org/10.1287/mnsc.1080.0886

[6] Li, C. and Zhang, F. (2013) Advance Demand Information Price Discrimination and Preorder Strategies. Manufacturing \& Service Operations Management, 15, 57 71. https://doi.org/10.1287/msom.1120.0398

[7] Gallego, G. and Ozer, O. (2001) Integrating Replenishment Decision with Advance Demand Information. Management Science, 47, 1344-1360. https://doi.org/10.1287/mnsc.47.10.1344.10261

[8] Boyaci, T. and Ozer, O. (2010) Information Acquisition for Capacity Planning via Pricing and Advance Selling, When to Stop and Act. Operations Research, 5, 1328 1349. https://doi.org/10.1287/opre.1100.0798

[9] Moe, W.W. and Fader, S. (2002) Using Advance Purchase Orders to Forecast New Product Sales. Marketing Science, 21, 347-364. https://doi.org/10.1287/mksc.21.3.347.138

[10] Yu, M. (2015) Rationing Capacity in Advance Selling to Signal Quality. Management Science, 61, 560-577. https://doi.org/10.1287/mnsc.2013.1888 


\section{Notation}

The following important notations will be used in the formulations:

\begin{tabular}{cc}
\hline Notation & Definition \\
\hline$\theta_{i}(i=1,2)$ & The type of retailer (1: high quality retailer; 2 : represents low quality retailer $)$ \\
$m_{i}(i=1,2)$ & The type of signal \\
$a$ & Advance purchase in pre-sale period \\
$C_{i}(i=1,2)$ & Wait in pre-sale period \\
$\beta$ & The cost of product \\
$V_{i}(i=1,2)$ & Consumer's valuation of product \\
$M$ & The quantity of consumers in pre-sale period \\
$N$ & The quantity of consumers in normal sale period \\
$P_{i}^{a}(i=1,2)$ & Pre-sale price \\
$P$ & The normal sale price of high quality product \\
$\sigma P$ & The normal sale price of low quality product \\
$r$ & The effect coefficient of negative review \\
$t$ & The ratio of high quality and low quality
\end{tabular}

Submit or recommend next manuscript to SCIRP and we will provide best service for you:

Accepting pre-submission inquiries through Email, Facebook, LinkedIn, Twitter, etc. A wide selection of journals (inclusive of 9 subjects, more than 200 journals)

Providing 24-hour high-quality service

User-friendly online submission system

Fair and swift peer-review system

Efficient typesetting and proofreading procedure

Display of the result of downloads and visits, as well as the number of cited articles Maximum dissemination of your research work

Submit your manuscript at: http://papersubmission.scirp.org/

Or contact jssm@scirp.org 